\title{
Performance of Private Higher Education Institutions and the School Heads' Supervision in South Central Mindanao
}

\author{
Fahad Abdul Salendab', Yolanda Cruspero Dapitan² \\ ${ }^{1,2}$ Sultan Kudarat State University
}

\begin{abstract}
The study aimed to assess the influence of instructional and administrative supervision on institutions' performance in private higher education in South Central Mindanao in terms of program accreditation and passing the national licensure examination. This research utilized ex-post facto research and the descriptive-correlation method. The research respondents were the 410 school heads. The collected data were analyzed using SPSS.

School heads demonstrated adequate instructional and administrative supervision of the teaching-learning process in private higher education institutions. Moreover, higher education programs are primarily level 1 and level 2 accredited. Many of these programs are primary education, engineering, accountancy and business, nursing, and graduate degree programs. The majority of the HEIs had 50\% and below the passing rate in the various programs that require licensure examinations for the last three years (2014, 2015, and 2016), while few HEIs had a passing rate of more than 50\%. HEIs passers were mostly graduate in education, accountancy, nursing, medical technology, engineering, radiologic technology, pharmacy, social work, physical therapy, nutrition, and dietetics.

Although higher education institutions obtained lower accredited programs, instructional and professional development supervision are good predictors of accreditation programs and licensure examination. Monitoring and leading activities are good predictors of program accreditation, while monitoring and organizing are good predictors of the licensure examination.

It is recommended that supervision must be sustained and strengthened among regulated HEIs to get their programs accredited and improve performance in the licensure examination.
\end{abstract}

Keywords

Performance, Supervision, Higher Education Institutions, Licensure Exam, Accreditation, South Central Mindanao

Article Received: 10 August 2020, Revised: 25 October 2020, Accepted: 18 November 2020

\section{Introduction}

Higher education institutions (HEIs) play a critical role in preparing a nation to be actively serious in producing gifted human capital assets (Conchada et al., 2015). Accordingly, each nation contributes primarily and meaningfully through these institutions for the development and awareness of its people, ensuring the future of the country

According to Conchada et al. (2015), this challenge is difficult because the higher learning institutions must continuously check themselves with the established requirements or standards and must subscribe themselves with the current labour market demands, which involves a considerable amount of money to improve its faculty, research, development and extension services.

Furthermore, according to Paqueo et al. (2012), most higher education institutions are of poor quality, as demonstrated by low board exam passing rates, and accrediting agencies have accredited only a few accredited programs. In response to these concerns, government agencies such as the Commission on Higher Education (CHED) have taken measures to enhance higher education institution's efficiency and ensure that these institutions adhere to specific requirements or standards to enhance the educational standard, Reforms such as rationalizing higher education's structure and enhancing the budget of these HEIs were implemented to make sure that mobilization and cost-effectiveness are both guaranteed, according to Paqueo et al. (2012). Since funding comes primarily from fees charged to these institutions, instituting reforms and introducing innovations to boost their education quality remains a tall order for private higher education institutions.

Furthermore, reforms would be insufficient unless the higher education institutions are continually pushed to change and set higher expectations than the minimum standard.

Accreditation is one way for private higher education institutions (PHEIs) to sustain compliance with the minimum standard. With the country's rising number of HEIs and the global market's demand for skilled employees, improving education quality is a must (Paqueo et al. 2012) 
As a reaction to the critics on quality education and the downward trend in education performance, Sule (2013) expressed her view that school supervision (internal or external) serves as an actual instrument to monitor the higher learning institutions' overall performance or operation. This is also the view of Yap (2012), who claims that the low standard of education hampers economic development. Thus, establishing a supervision mechanism will increase the standard of quality of higher education institutions.

For a school system to continue to provide quality education, supervision is highly indispensable. Supervision and administration provide leadership and training among teachers and school heads. It improves the organizational skills in order to cope up with the latest educational challenges and demands. Supervision also takes the lead in improving the teaching-learning environment, modifying the school curriculum to subscribe to the demands of the global market, and developing instructional materials for effective and efficient delivery of lessons (Banez, (2002) as cited by Visco (2015). Supervision has evolved into a cutting-edge process and a pivot on which output is based (Ankoma-Sey et al., 2016)

On the other hand, education stakeholders have recently expressed their dissatisfaction with educational institutions' poor results. Some blamed teachers and administrators, while other blamed students and their parents. Regardless of who is to blame, the truth remains that the school and its supervisory management are related to students' academic performance, which leads to their success in national licensure examinations and the accreditation of various higher education programs.

This study is unique to address the need for more efficient instructional and administrative supervision issues in Private Higher Education Institutions (PHEIs) in South Central Mindanao. These issues and the issue of whether or not such supervision relates to the institutions' institutional performance regarding their accreditation of programs and performance of graduates passing board or licensure examinations. Research and discussions are only discussed to demonstrate an educational institution's dedication or when an educational problem arises. In this light, the researcher considers this study to be essential and worthwhile for further research.

\section{Theoretical Lens}

Collegial Supervision and E. Thorndike's stimulus-response (S-R) theory were premised as this study's theoretical frameworks.

According to Ankoma-Sey and Maina (2016), heads cannot work in isolation; they cannot have field day supervision without supervising their subordinates, especially their teachers. They quoted many experts in the supervision discipline who advocated collegial supervision.

Further, Sergiovanni et al. (1993) claimed that encouraging teacher collegiality is an effective way to improve the school. According to them, collegial supervision is described as high cooperation among teachers and between teachers and school heads; mutual respect, common work principles, collaboration, and open dialogue about teaching and learning are all essential factors to consider.

Cooperative professional development promotes teacher growth through systematic cooperation with colleagues, according to Ankoma-Sey and Maina (2016), which involves many strategies, including professional dialogue, curriculum development, and input and action research projects. One central question that has yet to be answered is how collegiality will help students perform better. Collegiality is a thing to get teachers and administrators to collaborate. It is another way to transform collaboration into best practices and high academic results.

Although working in a group has its drawbacks, Goldhammer (1980) maintained that the most telling mark of a practitioner's dedication and fitness to do the professional work is the willingness to have the work evaluated and critiqued by other qualified workers.

Baffour-Awuah (2011) summarizes the research on collegiality by quoting Fullan, who claims that social interaction impacts what one does and contributes to learning something different. Fullan states that the theory of change stresses the importance of peer relationships in the classroom and that interaction is the cornerstone for social learning. Teachers take turns serving as clinical supervisors while assisting one another in collegial supervision.

Participation requires even more training in conferencing, information gathering, and other supervisory techniques, according to Servionanni, as cited by Baffour-Awuah (2011). He claims that 
in order for teachers to be a clinical supervisor, they must undergo appropriate training, which requires time and experience

\section{S-R theory (Stimulus-Response)}

The stimulus-response (S-R) theory of Edward L. Thorndike, based on conditioning principles, was also used in this research. Human behaviour is believed to be taught, according to this theory. The law of effect, which claimed that the behavioural reactions (R) that were accompanied by a satisfactory outcome were more likely to become established patterns and recur in response to the same stimulus (S)

According to the editors of the Encyclopedia Britannica last update:5-4-2015 https://www.britannica.com/topic/conditioning\#re f154466). Conditioning concepts are based on stimulus-response (S-R) theories. They are based on the idea that human actions can be taught. American psychologist Edward L. Thorndike, one of the field's early contributors, proposed the law of effect, which claimed that behavioural responses (R) closely accompanied by a satisfactory outcome were more likely to become established patterns and recur in response the same stimulus (S). The unmediated S-R scheme is the most simple S-R scheme. The response is mediated when a single organism (O) affects another stimulus somehow, such as by thinking about a response.

Individuals and organizations often use the S-O-R behaviour theories to explain social interaction. Conditioning is a type of learning in which a stimulus becomes more successful at eliciting a response, or response occurs more frequently in a well-defined and stable environment. The result will be determined by the type of reinforcement used. When two stimuli are viewed in an appropriate time and intensity relationship, one will inevitably evoke the same response as the other. A stimulus substitute process can be defined as a result of this process. Classical conditioning is the name given to this method.

Supervision is the task of ensuring that the program is appropriately followed and helping others. In order to achieve educational goals, inspection and supervision are distinct but complementary. Inspection is concerned with factfinding, while supervision is concerned about creating a productive superior-subordinate relationship with a particular focus on specialization to optimize the utilization of available human and material capital to achieve the organization's objectives (Oghuvbu, 2000).

Also, supervision is more comprehensive and focused on the school as a learning community. Burke and Krey (2005) agree that supervision is instructional leadership that relates perspectives to behaviours, reflects on procedures, contributes to, supports organization actions, directs interactions, provides instructional program improvement and maintenance and assesses goal achievement.

Furthermore, according to the International Institute for Educational Planning (2007), supervision is characterized as a combination of administrative practices and instructional supervision. According to IIEP (2007), supervision activities can be divided into monitoring and evaluation, advice, and teachers and headteachers. Also, supervision's primary aim is to enhance the teaching-learning process and encompass the entire spectrum of activities in the school, from the most administrative to instructional or pedagogical ones.

According to Sule (2013), instructional supervision holds a unique position in the educational system. It is described as improving teachers' professional development, curriculum, and teaching techniques through democratic interactions between the teachers and the supervisor (Okendu, 2012). Nakpodia (2006) added that instructional supervision in the modern era focuses on improving the teaching-learning situation to benefit both teachers and learners. It aids in identifying teachers' strengths and weaknesses and follow-up activities aimed at improving identified areas of teachers' weaknesses and giving recognition to the teacher.

According to the National Open University of Nigeria (NOUN, 2006), as Archibong (2010) cited, supervision allows teachers to be groomed through critical monitoring of instructional process and classroom experiences to carry out their teaching tasks following professional codes conduct. If schools are not adequately monitored, it can have adverse effects on students' output, and the educational goals will not be met; thus, various instructional, supervisory methods should be used to ensure that teachers have quality and quantity service. Since instructional supervision is the leverage point for instructional development, teacher competence, and educational system performance, and because unsupervised 
instruction can degrade educational quality, it is suggested that school heads catalyze the implementation of instructional activities geared toward an efficient and viable educational system. Instructional procedures and supervision enormously aid the student's academic performance. This is because supervision of instruction seeks to enhance teaching and learning through adequate guidance and preparation and devising ways of professionally developing teachers, thereby assisting them in developing creative abilities so that the instructional process will be enhanced.

Meanwhile, Okendu (2012), citing NOUN (2004), defines school administration as a social process involving the identification, maintenance, simulation, control, and unification of formally or informally organized human and physical energies within an interpreted system. Students, laws and regulations, and policies that control the school system are all handled by the school administration. School administration is a complex job that entails complex and challenging tasks such as student management, school staff, instructional program, school facilities, and statutory records.

\section{The Research Problem}

The study's main aim was to assess the influence of instructional supervision and administrative supervision on the accredited programs' level and passing rate in the licensure examination of the private higher education institutions (HEIs) in South Central Mindanao.

Specifically, this study attempted to answer the following questions:

1. What is the extent of instructional supervision manifested by the school heads in terms of:
a. Instructional Development;
b. Professional Development; and
c. Curriculum Development?

2. What is the extent of the administrative supervision manifested by the school heads in terms of:
a. Planning;
b. Organizing;
c. Leading; and
d. monitoring?

3. What is the level of institutional performance of private higher education institutions in terms of:

a. Programs accredited; and examination?

b. Passing rate in the licensure

4. Do instructional supervision and administrative supervision influence the level of accredited programs of HEIs?

5. Do instructional supervision and administrative supervision influence the level of passing rate in the licensure examination of HEIs?

6. Which among instructional supervision and administrative supervision variables best predict the levels of accreditation of programs and passing rate in the licensure examinations?

\section{Related Literature}

The narrative on the development of HEIs program accreditation is focused primarily on Conchada and Tiongco's analysis (2015), "Institutions of various types and natures are the subject of several accrediting agencies in the Philippines," according to these authors. In education, where there are elementary, secondary, and higher education institutions, various accrediting agencies are responsible for each. Several institutions stand to fulfil the purpose or function of accrediting HEIs, such as PAASCU and ACSC-AA.

The author cited Arcelo (2003), who traced the beginnings of Philippine HEI quality assurance to 1957 when the Philippine Accrediting Association of Schools, Colleges, and Universities (PAASCU) was established by the Catholic Educational Association of the Philippines (CEAP), which was made up of catholic HEIs. As the establishment of HEIs became a trend among religious congregations, accreditation was heavily based on non-secular, religious institutions. However, he did note that the Philippine Association of Colleges and Universities (PACU) was established in 1950 to serve non-sectarian higher education institutions (Conchada and Tiongco, 2015 quoting Arcelo, 2003). The Philippine Association of Colleges and Universities- Commission on Accreditation (PACU-COA) and the Association of Christian Schools and Colleges - Accrediting Agency (ACSC-AA), according to Corpus (2003), were established in 1973 and 1976, respectively. The Federation of Accrediting Agencies in the Philippines was established in 1977 when PAASCU, PACU-COA, and ACSC-AA were merged into one organization, the Federation of Accrediting Agencies the Philippines (FAAP). 
The Accrediting Agency of Chartered Colleges and Universities in the Philippines (AACCUP), founded in 1987 and formally organized in 1989, provided state universities with their accreditation agency not long after (Conchada and Tiongco, 2015 citing Corpus, 2003). In 1995, AACCUP became a member of FAAP.

The Commission on Higher Education (CHED) was founded in 1994, as mandated by the Higher Education Act of 1994, and was granted the autonomy to become the highest organization above accrediting agencies (Arcelo et al. 2003 as cited by Conchada and Tiongoco, 2015).

Higher Education Institutions (HEIs) accreditation has four levels. Regarding the accreditation application, on-site visitors to the institutions requesting accreditation would be present or required. If the HEIs receives positive results or reviews, it is given a Level I rating. FAAP receives the results, which are then forwarded to CHED for approval. This level is valid for two years; Level 2 degree of accreditation follows the same protocol as Level I, but this level will last up to 3 years. Level III is determined by graduates' excellent success on licensure exams at a specific university, research initiatives, linkages with other schools and agencies, a well-equipped library, community extension services, publication, and a top-notch faculty development program. The Level IV degree of accreditation will necessitate substantial study and publications programs, globally recognized teaching and learning methodologies, global linkages, and regional and national contributions of social and educational privileges. HEIs will compete with the best international universities (Conchada and Tiongco, 2015).

There is no need for colleges and universities to be complacent despite having achieved a high degree of accreditation since HEIs accreditation levels could be downgraded in the future. When the time comes, organizations must re-process the accreditation application.

\section{Accreditation Practices}

In the Philippines, HEIs accreditation is rewarded with autonomy, whereas other quality evaluation types are rewarded with support and subsidies, in contrast to what other countries do. As previously stated, accreditation of programs or institutions is voluntary, though CHED strongly encourages them to do so.
An accrediting agency operates in a slightly different manner than the others. According to Conchada and Tiongco (2015), citing Arcelo (2003), all accreditation agencies follow two steps: (1) a self-study by the assigned department for accreditation, usually in the form of a survey tailored to the HEIs structure, and (2) an on-site evaluation by the representatives from the accrediting agency.

Approximately five representatives of the accrediting agency consult with the self-study board and officials during the on-site evaluation. Once this has begun, the representatives are free to roam the campus and are given the authority to question any university member, including students, staff, and faculty members. They may also approach any student to ask about different accreditation areas. After the on-site evaluation, the representatives will meet the HEIs board of directors and other prominent officials to review the assessments' conclusions and findings. If the HEI's system has a significant weakness, they are given two years to correct it before being eligible for certification. Applying for Levels II-IV follows the same process (Arcelo, 2003 as cited by Conchada and Tiongco, 2015).

In the Philippines, several accrediting agencies cater to various HEIs. The Federation of Accrediting Agencies in the Philippines is the umbrella organizations for the three accrediting agencies in the Philippines, namely, the Philippine Accrediting Association of Schools, Colleges, and Universities (PAASCU); the Philippine Association of Colleges and Universities Committee on Accreditation (PACU-COA) and; the Association of Christian Schools, Colleges, and Universities Accreditation Commission (ACSCU-AAI)

\section{Supervision Defined}

Education is a vital component of national development in our country. Along with education is the supervision of the school heads to monitor the entire operation of the school. The success of the school depends on the supervision of the school heads. Various authors have defined supervision as an inspection, direction,

In this study, supervision is characterized as a mix of administrative practices and instructional supervision. According to the International Institute for Educational Planning (2007), supervision activities can be divided into 
two categories; monitoring and assessment, on the one hand, guidance and support for teachers, and headteachers on the other. Since school supervision's primary aim is to enhance the teaching-learning process, it must encompass the entire spectrum of activities in the school, from the most administrative to strictly pedagogical ones.

According to Oghuvbu (2001), supervision includes assessing the curriculum's practical application and supporting those implementing it. He said that supervision and inspection are distinct but complementary approaches to achieve educational goals. Inspection, according to him, is concerned with fact-finding. In contrast, supervision is concerned with creating a productive superior-subordinate relationship, focusing on specialization oriented toward the utilization of available human and material capital in achieving organizational goals.

Modern supervision concepts are more detailed and place a greater emphasis on the school as a learning community. Burke and Krey (2005) describe supervision as instructional leadership that connects perspectives to behaviour, focuses on process, responds to, supports organizational activities, coordinates interactions, provides instructional program changes and maintenance, and assesses target achievement.

Glickman et al. (2010) describe supervision as a school feature that enhances teaching by providing direct assistance to teachers, promoting community growth, providing professional development, designing curriculum, and conducting action research. Sergiovanni and Starratt's (2007) concept is similar to Glickman et al., but the latter emphasizes appreciation, caring, and teacher support. They point out that supervisors and teachers working together will improve the learning experience by making it more friendly, caring and respectful of students, and supportive of a leadership culture.

According to Sergiovanni and Starratt (2007), supervision is regarded as a collaborative effort in which supervisors and teachers collaborate to enhance teaching, leading to better student performance and school success. They highlighted the value of monitoring in achieving academic achievement.

Furthermore, according to Rettig (2007), supervision helps teachers be groomed through a discursive analytical study of classroom interaction to carry out their teaching tasks according to professional codes of conduct. If the schools are not adequately supervised, it will harm students, and the educational goals will not be achieved. Therefore, various supervisory methods should be used. Many school heads disregard instructional supervision, resulting in poor instructional performance by teachers in the schools. By keeping records of teachers and students in school, supervision aims to maintain and improve the teaching-learning process. The philosophy underpinning supervision is that all people in the educational system, whether students, teachers, school heads, managers, or supervisors, are valuable individuals with unique talents and abilities.

According to the National Policy on Education (FRN, 2004), supervision is intended to ensure quality control of instructional and educational programs through routine inspection and continuous monitoring. The school heads use various supervisory techniques to monitor both teaching and non-teaching personnel in the school system, ensuring that they adhere to universally accepted educational standards. School heads also ensure that the school maintains high standards by adhering to established rules and regulations.

To Ojogwu (2001), supervision helps teachers become more knowledgeable of sound educational philosophies and educational policies and their schools' changes. According to Nakpodia (2006), supervision is the school administration component responsible for the appropriateness of educational program instructional standards.

Akinwumi (2002) defines supervision as all designated school officials' attempts to provide leadership to teachers and non-teaching staff to improve instruction. It entails the stimulation of instruction, the stimulation of teacher's professional growth and development, the collection and revision of educational goals, instructional materials, and instruction evaluation.

Finally, school heads supervise teachers by reviewing their work schedules and lesson plans, ensuring that they attend classes on time, monitoring absenteeism, praising hardworking teachers, punishing indolent ones, delegating administrative tasks to them, and motivating them to do the right things at the right time. He provides materials necessary for the successful completion 
of assigned tasks and promotes experimentation. Both of these factors contribute to the educational system's overall quality.

\section{Principles of Educational Supervision}

According to Sergiovanni and Starratt et al. (2002), supervision is regarded as a joint venture in which supervisors and teachers participate in a formal and professional dialogue to improve teaching, leading to better learning and performance.

According to De Grauwe (2001), all countries, especially developing ones, prioritize improving school quality and student performance because the learning outputs are mainly dependent on the quality of education provided. Higherquality education. According to Barro (2006), it fosters economic growth and development, but quality education depends on good teachers trained and supervised, as they are one of the most critical inputs to education delivery.

According to De Grauwe (2001), national authorities depend heavily on the school supervision system to track both the quality of schools and the key indicators of their performance, such as student achievement. According to Sergiovanni and Starrat (2002), supervisors typically inform, assist, and support teachers to achieve the goal of supervision. Supervisors should also inspect, control, and assess teachers, according to UNESCO (2007). This theory assumes that educational goals can be accomplished under school heads' successful leadership, leading to its progress.

On the other hand, the principles of supervision serve as the guide to the different activities aimed at improving instruction and, as a result, promoting the teaching-learning process of the school enterprise. Peretomode (1995) proposes a set of guiding principles for the school heads' successful supervision. A healthy workplace and environment, staff orientation, constructive feedback, an opportunity for improvement, motivation, and encouragement are only a few of them.

Besides, educational supervision is concerned with the overall development of the teaching and learning environment. Educational supervision, according to Berhanne Assefa (2014) in her study "Practices and Challenges of Instructional Supervision," has the following principles: there should be short-term, mediumterm, and long-term planning for supervision; supervision is a sub-system of school organization; all teachers have a right to and a need for supervision; supervision should be conducted regularly to meet the individual needs of teachers and other personnel; supervision should assist the supervisor and teachers in clarifying educational objectives and goals.

In general, since supervision is concerned with enhancing the instruction, this supervision should be improved at the school level, provide equal opportunities for all teachers to be supported, be performed regularly to optimize teachers' competency.

The Ministry of Education (2010) has also established the fundamental concepts of educational supervision. Such principles include: supervision is cooperative, in which the supervisor is expected to collaborate with senior teachers, department heads, unit leaders, vice directors, and administrators at the local level to identify instructional problems and prepare training based on the identified gaps in order to minimize problems while working together to improve the quality of education. This helps to adapt to the changing environment; supervision should be democratic, with every member having the ability to share their ideas openly. While performing his duties, the supervisor is expected to consider various factors such as supervision is an approach in which the supervisor is expected to not only provide guidance but also to take feedbacks from the teacher. Finally, supervision is an evaluative and scheduled process in which supervisors are required to collect data from students, staff, parents, teachers, and school managers to obtain information and observe the school's situations.

\section{On Instructional Supervision}

One of the several methods used to achieve the educational goal is instructional supervision. According to Harris (1995), school supervision aims to sustain and enhance its teaching-learning process. This is also the position taken by Rettig (2007) that supervision is an orchestrated behaviour system that deals with the teaching behaviour system to enhance the student's learning situation.

Instructional supervision, according to Omoregie (2005), is an internal process. The internal process is concerned with the regular use of resources and processes in a school and the maintenance of lines of action that facilitate productivity. As a practice, the school head has a 
supervisory position within the school regarding educational development and assessment. He also noted that school supervisors should help teachers evaluate the best teaching strategies, equipment, physical environments, and classroom characteristics that are most likely to facilitate school effectiveness.

Adetula (2005) agrees with Omoregie that instructional supervision is an internal tool used by the school heads for self-evaluation to evaluate teachers and students in improving their teaching and learning practices to meet the educational goals. According to Adetula (2005), the school heads maintain successful supervision by engaging academically and socially with the teachers and students daily both within and outside the classrooms. The primary goal is to track curricular implementation, ensure the desired improvement in teachers' capacities, upgrade their conceptual knowledge and teaching skills, and provide them with assistance in their work so that teachers' pedagogical practices and students' learning outcomes in school settings will improve.

Furthermore, instructional supervision is intended to supervise, assist, and influence teachers' instruction in the classroom in order to increase students' performance. According to Sergiovanni and Starratt (2007), instructional supervision is a compilation of tasks and role specifications to influence instructions. Sergiovanni and Starratt (2007) quote Ben Harris as saying that supervision aims to sustain and enhance its teaching-learning processes. The school administration process, known as supervision, focuses primarily on achieving the educational system's acceptable instructional standards.

As a result, instructional supervision has become a critical component in enhancing the quality of school instruction. It entails ongoing academic support for teachers as well as success and progress evaluations for the school. In contrast to a summative inspection, it is formative and interactive. According to Glickman (1990), instructional supervision is the activity that enables teachers to enhance teaching while providing quality education for students and an act that strengthens relationships and meets both personal and organizational needs.

Sergiovanni and Starratt (2002) define instructional supervision as opportunities for teachers to develop their capacities to contribute to students' academic success. Furthermore, as Yavuz defines in Garubo and Rothstein (2010), instructional supervision is a method of teaching the staff to act in more conscious ways by providing teachers and supervisors with more knowledge and deeper insights into what is going on around them. This broadens the variety of resources available to teachers when interacting with students. When supervisors and teachers work together, teachers learn to recognize and solve problems, and supervisors gain a greater understanding of what is going on in various classrooms. Similarly, (MOE 2005) described instructional management as a tool for improving and monitoring teaching and learning efficiency and quality at all educational system levels. Consequently, effective school management, which is critically interdependent on quality supervision, results from effective school management.

A cursory examination of instructional supervision practices that the school head serves as a change agent for teachers' professional development and curriculum implementation enhancement is the core objective of instructional supervision.

\section{On Administrative Supervision}

Supervisors are critical players in the school setting's administrative process, and they are often tasked with providing the necessary environment, equipment, and services for successful teaching-learning.

According to Lennox (2013), managers, administrators, or supervisors perform some essential functions in organizations and are guarded as having a significant impact on the workplace's overall environment. Tess (2003) asserted that administrators/supervisors must empower employees to use their creativity and initiative to generate inputs to achieve institutional goals.

Roe (1961), on the other hand, claims that administration is a mechanism that uses leadership, teamwork, and control to guide the efforts of individuals within an organization toward a common objective.

According to Girling (1991), the administration includes planning, coordinating, delegating, evaluating, supervising, guiding, and controlling. Furthermore, according to Mussazi 
(2002), as an administrator, the school head is responsible for ensuring that the established procedures and structures assist the school in achieving its objectives and goals. As an administrator, he is also responsible for maintaining the school and ensuring that its runs smoothly. He is in charge of coordinating and regulating the entire school system's work.

Mussazi (2002) also believes that administration is an essential component of any organization. Complex institutions such as schools, universities, and other institutions must sustain and improve their effectiveness and productivity.

Sergiovanni (2002) believes that
administrators' interpretations when they
transform theoretical understanding into realistic decisions and activities are critical to administrative actions' effectiveness. Segiovanni considers supervisory and administrative behaviour, school priorities, limited resources, and the need to collaborate with others, such as teachers, parents, and students, to be essential administration elements.

Administrators/supervisors are deemed effective when they are competent in aligning their activities with their objectives.

While the administration is an essential component of all institutions and organizations, school administrators have never been a more significant challenge. Supervisors must also collaborate with the school boards and teacher units. They must also keep track of these systems. External organizations such as unions and politicians seek to influence educational administration's content and structure and redistribute educational resources.

According to Uyanga (2007), a school supervisor is a planner, director, controller, coordinator, organizer, adviser, and problem solver by definition. The supervisor is the individual who is responsible for the school's entire administration, as well as its success or failure. The supervisor defines and sets the school's priorities and objectives, consistent with national goals, analyzing task assignments, and distributing responsibilities among the staff based on specialization and expertise.

Administrative roles have been discussed in various researches and studies. According to Olaleye (2013), the school head is the school's chief executive officer, instructional leader, and personnel manager for both students and staff members.

The administrators of the school's finance and facility are all the individuals. He must establish a positive relationship with the immediate community and maintain contact with the higher education commission in the area where the school is located. In the educational system, there are many types of administrative tasks. Student personnel, staff personnel, instructional and curriculum development, school finance and business management, school facility, and other general tasks are all administrative functions.

In general, the school head is a standardsetter who guides the development of aspiration and expectation among teachers and students to do excellent work. He is the one who helps teachers with their problems of developing methods, resources, and evaluation and thus ensures that consistency is maintained. Heads of schools may guide teachers in honing their skills and developing their ability to evaluate and interpret data. The school head must possess specific administrative skills to fulfil his duties efficiently.

\section{School Head's Administrative Roles}

Regardless of whether they run a primary, secondary, or tertiary school, school heads must fulfil their duties. The school head performs specific duties, meets specific needs in higher education, bears specific obligations, and is required to function in certain ways. Several researchers accompanied school heads around for an extended period and recorded everything.

Sergiovanni (2009) and Tareilo (2010) created a definition of school heads' work that can be broken down into three categories. Heavy workload and a fast pace are examples of such characteristics. According to Sergiovanni (2009), school heads handled over twenty pieces of mail a day, attended various meetings, and took a regular tour of their school building. Sergiovanni says that free time was limited and that even though time pressure was limited, and even though time pressure was temporarily eased, there were always tasks that needed to be done.

Variety, fragmentation and brevity are the second characteristics. According to Tareilo (2010), research on school administrator behaviour consistently identifies the administrator's demands as fragment-rapid-fire 
and voluminous, with little time for quiet reflection. According to Lunenburg (2008), school heads participate in at least 149 different events every day, most of which take less than five minutes. This contrasts to many technical and professional work, which are characterized by long periods of focus. School heads shift gears quickly; their work does not follow a clear pattern. A significant crisis is interspersed with minor occurrences in an unpredictable order. Any problem must be addressed as soon as possible.

Finally, oral communication must be examined, as school leaders spend 70 to 80 per cent of their time in interpersonal communication. According to Ubben et al. (2011), school heads invest 70 to 80 per cent of their time on interpersonal communication. Colleagues from other schools, senior administrators, staff experts, teachers, and other school employees are personal contacts. According to them, effective school heads develop personal communication outside of the school, including lawmakers, the state department of education staff, parents, and community members. Face-to-face and mobile communication are more common than written communication. Written communication is slow and time-consuming, while oral communication is fast and action-oriented. Further, school administrators rely heavily on rumours and hearsay because of the timeliness of oral communication. Oral communication is more direct and fulfils people's social interaction needs.

\section{Methods}

Since the researcher investigated accessible documents on accredited programs and performance in the licensure examination of private higher education institutions (PHEIs) in South Central Mindanao from Calendar Year 2014-2016, the researcher used ex-post facto analysis approach or the causal-comparative method

The descriptive-correlation approach was also used to determine the impact of school heads' instructional and administrative supervision on the

Table 1

$$
\begin{aligned}
& \text { Extent of Instructional Supervision of the School Heads } \\
& \qquad \mathrm{n}=410
\end{aligned}
$$

passing rate of licensure exams and the level of programs accredited. The descriptive-survey method was used to determine the level of instructional and administrative supervision, as demonstrated by the school heads, as well as the number of approved programs and the passing rate on the licensure exam. Key informant interviews were also used to obtain from the school heads to justify the respondents' responses.

Thirty (30) presidents, thirty (30) vice president for academic affairs, fifty (50) college deans, one hundred (100) program heads, one hundred (100) school coordinators, and one hundred (100) chairpersons took part in the survey. These respondents came from 30 private higher education institutions. A total of 410 school heads took part in this research.

The data gathered were analyzed using SPSS version 18. Frequency count and percentage, mean, and regression analysis were the statistical methods used.

The survey questionnaire was formulated after reviewing the related literature and consulting with experts. The instrument was found to be accurate and valid, and it has been used in over 200 supervision studies. A sample dry run conducted. The questionnaire was administered to 30 school officials from private higher education institutions and then given to the same group after two weeks using the test and re-test method to validate the instrument. Using item-total correlation analysis, items that did not meet the required correlation coefficients were either discarded or improved while other items that met the required standards were retained. Further, a reliability test was performed to determine the instrument's reliability after items of the instrument were finalized. A reliability index of .97 was determined from this test, indicating that the instrument was very reliable.

\section{Results and Discussion}

\begin{tabular}{lll}
\hline Items & Mean & Description \\
\hline Instructional Development & 3.22 & Manifested \\
Professional Development & 3.16 & Manifested \\
Curriculum Development & 3.19 & Manifested \\
\hline
\end{tabular}




\begin{tabular}{llll} 
& \multicolumn{2}{l}{ Grand Mean } & \multicolumn{2}{c}{3.19} & Manifested \\
\cline { 2 - 5 } Legend: & $3.50-$ & 4.00 & Highly Manifested \\
$2.50-$ & 3.49 & Manifested & \\
$1.50-$ & 2.49 & Least Manifested &
\end{tabular}

$1.00 \quad$ - $\quad 1.49 \quad$ Not Manifested

Table 1 reflects the instructional supervision of the school heads in terms of instructional development, professional development, and curriculum development.

Based on the study results, the school heads' instructional supervision in terms of instructional development is manifested. The school heads' supervision of professional development was also viewed as manifested. Similarly, school heads exercised control over curriculum development.

Table 2

Extent of Administrative Supervision Manifested by the School Heads

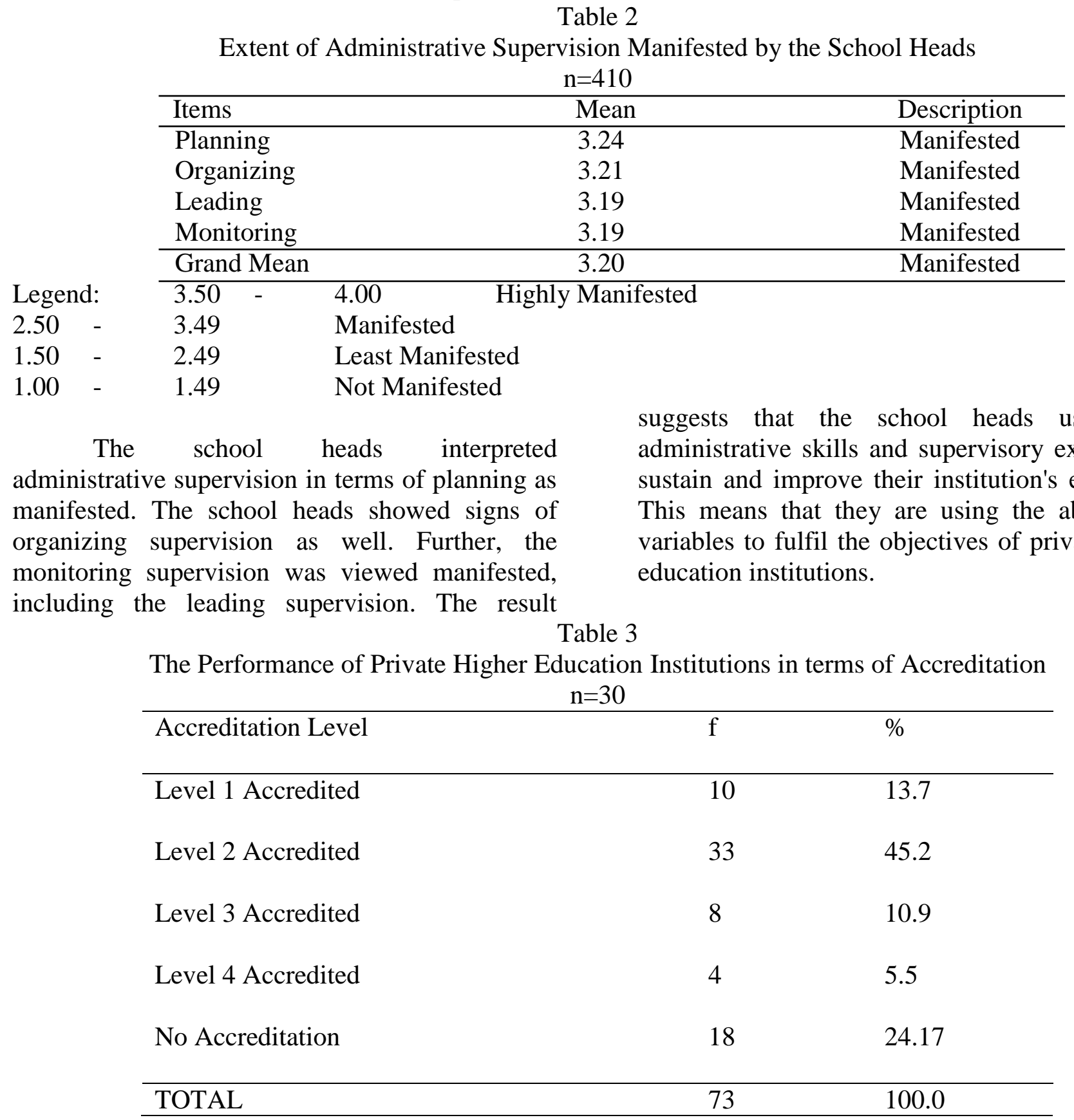

In general, this implies that school heads used their instructional, supervisory practices to enhance the institution's pedagogical practices by observing teachers, providing positive feedback, providing appropriate training to its constituents, and building a close relationship with them in order to support the teaching-learning process to achieve the institutions' objectives.

Legend: $\quad 3.50 \quad-\quad 4.00 \quad$ Highly Manifested

The school heads interpreted administrative supervision in terms of planning as manifested. The school heads showed signs of organizing supervision as well. Further, the monitoring supervision was viewed manifested, Table 3

The Performance of Private Higher Education Institutions in terms of Accreditation 
As to the performance of PHEIs in accreditation, 30 private higher educational institutions participated in this study. Some of these PHEIs were categorized as autonomous and deregulated; others were regulated mainly by CHED. In this study, these PHEIs were lumped together since only their accredited programs were needed in the study.

A total of 55 programs were accredited from the 30 private higher education institutions. Eighteen (24.17\%) of these programs by HEIs were not accredited. The primary reason for the nonaccreditation of their programs was their absence or non-membership of any accrediting agency.

Of the 55 programs that were accredited, 10 or 13.7 per cent were Level 1 accredited in South Central Mindanao. This means that HEIs after application for accreditation, on-site visitation were conducted on these institutions seeking accreditation. Further, these institutions received positive feedback, which is why they were issued the level I qualification. The findings were passed to FAAP and then endorsed to CHED. This level is good for two years. Programs are Computer Science, BS Information Technology, MAED, MPA, MBA, BS Computer Engineering, Accountancy, BSHRM, BS on Office Administration, BS in Nursing, BSBA, and BSED and BEED.

Meanwhile, 33 or 45.2 per cent of private HEIs' programs were level 2 accredited. This means that these HEIs, before they were granted Level 2, had undergone on-site visitation and evaluation resulted in their level 2 accreditation. This level of qualification can be renewed every three years. These accredited programs were: BS Industrial Engineering, BS Civil Engineering, BS in Accountancy, BS Computer Science, BS Information Technology, BS Electrical
Engineering, BS Electronics Engineering, $\mathrm{PhD}$ in Educational Management, MBA, MPA, MAED, BEED, BSED, AB, BSBA.

Furthermore, eight or 10.9 per cent of the programs of HEIs were level 3 accredited, which implies that HEIs performed well in licensure exams, conducted research projects, with close links to other schools and organization, a well-run library, community extension services, journals and a strong faculty development program These accredited programs by the autonomous, deregulated and even some regulated HEIs were: BS Nursing, BSBA, BS in Accounting Technology, AB History, English, Philosophy, Political Science, BEED, BSED, BS Biology, BS Psychology, Bachelor in Public Administration, $\mathrm{AB}$ Communications, $\mathrm{AB}$ Sociology, $\mathrm{AB}$ in Religious Study, BS in Accounting and Financial Management, and MAED.

Lastly, four $(5.6 \%)$ of the programs had level 4 accreditation. These programs were in Arts \& Science, Education, Business Administration offered by an autonomous HEI. This data suggests that these private HEIs had projects with substantial academic publications and intentionally recognized teaching and learning techniques, had global interconnections and contributed to regional and national social and educational advantages. The institution has the potential to compete with top-tier international universities. The data further explains that the autonomous and deregulated states have more accredited programs than regulated schools.

The findings above support the study conducted by Conchada and Tiongco (2015) that the quality of education of several higher education institutions have deteriorated over time because they have few accredited programs.

Table 4

Frequency of Licensure Exam Performance Rating of Programs

In Private Higher Education Institutions in the past three years (2014-2016)

\begin{tabular}{lll}
\hline Average Passing Rate & Frequency & Per cent \\
\hline $30 \%$ \& below & 28 & 27.7 \\
$31 \%-52 \%$ & 42 & 41.6 \\
$53 \%-76 \%$ & 22 & 21.8 \\
$77 \%$ \& Above & 9 & 8.9
\end{tabular}


As to the licensure examination passing rate, the levels of the passing rate of the 30 PHEIs in South Central Mindanao for the last three years (2014-2016) emanated from their graduates of education, accountancy, nursing, medical technology, engineering, radiologic technology, pharmacy, social work, physical therapy, and nutrition and dietetics.

For the last three years, 28 or 27.7 per cent of the passers of the graduates of PHEIs in various programs that required board examination had a passing rate of $30 \%$ and below. Forty-two

Table 5

Regression Analysis Between Instructional Supervision and Accreditation of Private Higher Institutions

\begin{tabular}{llllll}
\hline Instructional Supervision & B & $\begin{array}{l}\text { Std. } \\
\text { Error }\end{array}$ & t & Sig & Interpretation
\end{tabular}

\begin{tabular}{llllll}
\hline Instructional Development & -1.697 & .487 & -3.488 & .001 & Significant \\
Professional Development & -1.371 & .408 & -3.364 & .001 & Significant
\end{tabular}

Curriculum Development

.419

.677 Not Significant took the various board examination had a passing rate from 31 per cent to 52 per cent. On the other hand, 22 or 21.8 per cent of PHEIs from various programs obtained a passing rate of 53 per cent to 76 per cent in their licensure examination. Finally, only or $8.8 \%$ of the graduates of PHEIs took the licensure examination with $77 \%$ above the passing rate. This result validated Conchada et al. (2015) study when they concluded that most higher education institutions are of poor quality, as shown by low board exam pass rates.

$\mathrm{R}=.5 \overline{84}$

Adjusted $\mathrm{R}=.322$

$\mathrm{F}=17.88$

Sig F: $p=.001$

The relationship between the two variables was investigated using multiple linear regression analyses, the level of accredited programs and potential predictors such as the extent of manifestation of the school heads' supervision of instructional, professional, and curriculum developments. The descriptive statistics and research findings are summarized in table 5.

As revealed in Table 5, instructional development and professional development as sub-variables of instructional supervision manifested by the school heads when taken in combination significantly influenced the private higher education institutions' level of accredited programs.

All three predictors were included in the multiple regression model, which resulted in adjusted $\mathrm{R}^{2}=$ $.322, \mathrm{~F}=17.88, \mathrm{p}<.001$.

The multiple regressions suggest a moderate correlation between the extent of instructional supervision and the level of programs accredited variables, as its correlation coefficient of .584 indicates. Together, they account for 32.2 per cent

of the total variance of accredited programs while the remaining $67.7 \%$, respectively, are accounted for by other factors different from what were considered in this research study.

Further, the supervision of instructional development and professional development manifested by the school heads in private HEIs has significant negative weights (opposite in sign from its correlation with the criterion-level of the accredited program). This indicates that after accounting for curriculum development manifestation, the more the school heads' manifest instructional and professional supervision, the lower levels of accredited programs will improve (a suppressor effect). The beta coefficient for instructional development (-1.697) and professional development (-1.371) are significant at 0.001 probability level. The curriculum development supervision did not contribute to the accredited programs.

The obtained F-ration of 17.88, which was found significant at .001 alpha, indicates that the school 
heads' extent of manifestation in their instructional and professional development supervision formed

Table 6

a very significant set of predictors for accredited level HEIs programs.

Regression Analysis Between Instructional Supervision

And Licensure Examination of Private Higher Education Institution

\begin{tabular}{llllll}
\hline Instructional Supervision & B & $\begin{array}{l}\text { Std. } \\
\text { Error }\end{array}$ & t & Sig & Interpretation
\end{tabular}

$\begin{array}{lllllll}\text { Professional Development } & 1.150 & .269 & 4.270 & .000 & \text { Significant }\end{array}$

$\begin{array}{lllllll}\text { Instructional Development } & & 1.315 & .367 & 3.585 & .001 & \text { Significant }\end{array}$

$\begin{array}{llll}\text { Curriculum Development } & -.379 & .706 & \text { Not Significant }\end{array}$

$\mathrm{R}=.606$

Adjusted $\mathrm{R}=.354$

F-28.37

Sig F: $p=.001$

Multiple linear regression models were also used to analyze the relationship between the passing rate on the licensure exam and possible predictors such as the extent to which school heads' supervision was manifested in instructional, professional, and curriculum development. The descriptive figures and findings are summarized in table 6.

As revealed in Table 6, the extent of school heads' manifestation of supervision in terms of instructional development and professional development when taken in combination significantly influenced the private HEIs level of passing rate in the licensure examination.

All three predictors were included in the multiple regression model, which resulted in adjusted $\mathrm{R}^{2}$ $=.354, \mathrm{~F}=28.37, \mathrm{p}<.001$.

The multiple regressions suggest a moderate correlation between the extent of instructional supervision and the level of program accredited variables, as its correlation coefficient of .606 shows. Together, they account for 35.4 per cent of the total variance of the level passing rate in licensure examination while the remaining $64.5 \%$,

Table 7

Regression Analysis Between Administrative Supervision and Accreditation of Private Higher Institutions

\begin{tabular}{llllll}
\hline Administrative Supervision & B & $\begin{array}{l}\text { Std. } \\
\text { Error }\end{array}$ & t & Sig. & Interpretation \\
& & & & \\
\hline Monitoring & -1.765 & .504 & -3.500 & .001 & Significant
\end{tabular}




\begin{tabular}{|c|c|c|c|c|c|}
\hline Leading & -.968 & .454 & -2.133 & .037 & Significant \\
\hline Planning & & & .264 & .793 & Not Significant \\
\hline Organizing & & & .382 & .704 & Not Significant \\
\hline
\end{tabular}

$\mathrm{R}=.553$

Adjusted $\mathrm{R}=.286$

$\mathrm{F}=28.6$

Sig F: $\mathrm{p}=.001$

The relationship between the two variables was investigated using multiple linear regression analyses, accredited programs and potential predictors such as the extent of manifestation of school heads' supervision in planning, organizing, leading, and monitoring their administrative supervision. The descriptive figures and findings are summarized in table 7.

Monitoring and leading, when taken in combination, significantly influenced the private HEIs level of accredited programs. Table 7 shows the results.

The multiple regression model with all four predictors produced adjusted $\mathrm{R}^{2}=.553, \mathrm{~F}=28.86$, $\mathrm{p}<.001$.

The multiple regressions suggest a moderate correlation between the extent of administrative supervision and the level of accredited programs, as its correlation coefficient of .553 indicates. Together, they account for 28.6 per cent of the total variance of the accredited program level while the remaining $71.4 \%$, respectively, are

Table 8

accounted for other factors different from what were considered in this study.

Table7 shows that the independent variables monitoring and leading, which are manifested in the school heads' administrative supervision in the private HEIs, have significant negative weights (opposite in sign from its correlation with the criterion-level of the accredited program). This indicates that after accounting for planning and organizing manifestation, school heads who manifest more monitoring and leading supervision tends to improve the lower levels of accredited programs (a suppressor effect). Planning and organizing did not contribute to the level of accredited programs.

The beta coefficient for monitoring (-1.765) and leading (-.968) are significant at a 0.001 probability level.

The obtained F-ration of 28.6, which was found significant at .001 alpha, indicates that the school heads' monitoring and leading administrative supervision formed a very significant set of predictors for the level of accredited HEIs programs.

Regression Analysis Between Administrative Supervision and Licensure Examination of Private Higher Institutions

\begin{tabular}{llllll}
\hline Administrative Supervision & B & $\begin{array}{l}\text { Std. } \\
\text { Error }\end{array}$ & t & Sig. & Interpretation \\
\hline Monitoring & 2.006 & .264 & 7.593 & .000 & Significant \\
Organizing & .641 & .274 & 2.339 & .021 & Significant \\
Planning & & & 1.310 & .193 & Not Significant \\
Leading & & & 1.049 & .297 & Not Significant \\
\end{tabular}

$\mathrm{R}=.634$

Adjusted R=.389 
$\mathrm{F}=32.86$

Sig F: $p=.001$

The relationship between the two variables was investigated using multiple linear regression analyses; the passing rate in licensure examination and potential predictors such as school heads' extent of manifestation of administrative supervision in planning, organizing, leading, and monitoring. The descriptive statistics and findings are summarized in Table 8

As indicated in Table 8, the extent of monitoring and organizing of school heads' administrative supervision when taken in combination significantly influenced the private HEIs' level of passing rate in the licensure examination.

All four predictors were included in the multiple regression model, which resulted in adjusted $\mathrm{R}^{2}=$ $.389, \mathrm{~F}=32.86, \mathrm{p}<.001$.

The multiple regressions suggest a moderate correlation between the extent of administrative supervision and the level of passing rate in licensure examination, as its correlation coefficient of .634 denotes. Together, they account for 38.9 per cent of the total variance of the level passing rate in licensure examination while the remaining $61.1 \%$, respectively, are accounted for by other factors different from what were considered in this study.

As can be seen in Table8, monitoring and organizing of the administrative supervision by the school heads of private HEIs have significant positive regression weights, indicating that school heads who demonstrate more monitoring and organizing supervision is expected to increase the rate of passing in the licensure examination, after the other variables in the model have been taken into account. The passing rate on the licensure examination was not affected by planning and leading.

The beta coefficient for monitoring (2.006) and organizing (.641) are significant at a 0.05 probability level.

The obtained F-ratio of 32.86, which was found significant at .001 alpha, indicates that the school heads' administrative supervision formed a very significant set of predictors for the passing rate in the licensure examination.

Conclusions and Recommendations

Because of the results of this study, it is concluded that school heads demonstrate their ability to run instructional activities undertaken by curricular programs in order to enhance teaching and learning; they also demonstrate a strong show of their administrative skills supervision in order to help in the improvement of teaching and learning. On the other hand, PHEIs' programs are mostly level 1 and level 2 accredited with a limited period of 2 to 3 years to sustain, improve, and downgrade accreditation levels. Many of these programs are primary education, engineering, accountancy and business, nursing, and graduate degree programs. Few accredited programs were in level 3 and level 4. Most of these accredited programs are nursing, education, arts and sciences, accounting and financial management, and graduate degree in education. Furthermore, these accredited programs are offered chiefly by autonomous and deregulated HEIs, and very few being offered by regulated HEIs. A quarter of the 30 HEIs has no accredited programs or membership in any accrediting bodies.

Concerning the passing rate in the licensure examination for the last three years (2104-2016), PHEIs passers were mostly graduates in education, accountancy, nursing, medical technology, engineering, radiologic technology, pharmacy, social work, physical therapy, and nutrition and dietetics. The majority of the HEIs had a 50\% and below the passing rate in the various programs that require licensure examination for the last three years, while few HEIs had a passing rate of more than $50 \%$.

In the case of accredited programs, although HEIs had obtained lower levels of their accredited programs, the following contributed to the accreditation of their programs: (a) Instructional and professional development supervisions are good predictors of improving the level of accreditation of programs; (b) Monitoring and leading are good predictors of improving the accreditation level of the program

. In the case of passing the rate in licensure examination, although HEIs had obtained low passing rate, the following contributed to the level of passing rate in the licensure examination: Instructional and professional development are good predictors of improving the rate of passing in licensure examination; (b) Monitoring and organizing are good predictors of improving passing rate in the licensure examination. 
Since the school heads of private higher education institutions show manifestation in both instructional and administrative supervision, it implies the effectiveness in their efforts to provide quality education; this implies sustaining and improving supervision programs. It also implies that supervision might be a gateway towards accrediting more programs and improving the licensure examination performance. However, in program accreditation, most HEIs do not have accredited programs, which implies the need to work for their accreditation to meet standards set for providing quality education. As to the licensure examination, it is evident that most of the private higher education institutions have poor performance in the licensure examination. This implies a sustained effort to improve such performance.

It is recommended that HEIs should continue to improve its supervision program through sustain faculty development and training, acquiring adequate resources and materials for instruction, improving facilities, attuning teaching methodologies and strategies on the rapid pace of development of information technology, and providing needed administrative support, and strengthen the collaboration among HEIs stakeholders.

Most regulated private higher education institutions do not have accredited programs; if not, only a few programs are accredited and have a low percentage of passers in the licensure examination. These HEIs should work for accrediting their programs and improving the rate of passers in licensure examination through the following priority areas: constructing more facilities, buildings, continuing training of faculty and staff, requiring faculty to get graduate degrees in line with their field of specialization, improve teaching methodologies and strategies, acquire more instructional resources, such as books, teaching materials, etcetera, the conduct of research and community outreach programs and many others, the conduct of in-house reviews for the licensure examination.

A study is recommended in the private HEIs using other independent variables such as teacherrelated factors, like teaching strategies, technologies in teaching, leadership potentials of teachers, pre-service training and seminars, problems coping mechanisms of teachers, and other variables as predictors of the licensure examination. Also, the study is recommended on the status of accreditation of private HEIs in South Central Mindanao.

\section{References}

[1] Adetula, L. (2005). Improving the Supervisory Skills and Competencies of Inspectors of Mathematics Education in Schools. International Journal of the Teachers Registration Council of Nigeria

[2] Akinwumi, P. (2002). Supervision in Education. Salem Publisher: Ibadan, Nigeria

[3] Ankama-Sey, Vera Rosemary; Maina, Bashir. The role of Effective Supervision on academic performance of Senior High Schools in Ghana. Journal of Arts and Humanities, [S.1.], v. 5, n. 4, p. 73-83, Apr. 2016. ISSN 2167-9053. Available <http://theartsjournal.org/index.php/site/article/vi ew/932/467 Date accessed: 26 Mar. 2017

[4] Archibong, F.I.(2013) Strengthening Internal Quality Assurance For Improved Education Delivery In Nigerian Public Universities. Research on Humanities and Social Sciences: Vol.3, No.1, 2013

[5] Baffour-Awuah, Peter.2011. Supervision of Instruction in Public Primary Schools in Ghana: Teachers' and Headteachers' perspectives. A Published Doctoral Dissertation at Murdoch University. Ghana, August 2011.http://researchrepository.murdoch.edu.au/id/ eprint/8483/2/02Whole.pdf

[6] Barro, R. (2006). Education and Development: Quality Counts. Retrieved September 14, 2008 from

http:/www.worldbank.org/education/pdf/educatio $\mathrm{n}$

[7] Blasé, J. (1999). Principal's Instructional Leadership and Teacher Development: Teachers' Perspectives. Educational Administration Quarterly

[8] Conchada and Tiongco (2014). A Review of the Accreditation System for Philippine Higher Education Institutions. DISCUSSION PAPER SERIES NO. 2015-30. Philippine Institute for Development Studies, Surian sa mga Pag-aaral Pangkaunlaran ng Pilipinas. June 2015. http://dirp3.pids.gov.ph/webportal/CDN/PUBLIC ATIONS/pidsdps1530.pdf

[9] DeGrauwe, A.(2001). Supervision in Four African Countries: Challenges and Reforms Volume I, Paris: International Institute for Educational Planning/UNESCO

[10] FRN. (2004). National Policy on Education. Federal Ministry of Education 
[11] Glickman, C. (2002). Leadership for Learning: How to Help Teachers Succeed? Alexandria, VA. Association for Supervision and Curriculum Development.

[12] Glickman, C., et.al (2004). Supervision and Instructional Leadership: A Developmental Approach (6th Ed.) New York: Pearson Education Inc.

[13] Iheukwumere, C. (2006). Principles and Practices of School Administration. Awka: UPSLennox, H. (2013). Intellectual Capital in a Recession. Evidence from UK. SMEs. Journal of Intellectual Capital Lunenburg, Fred C., 2010. Formal Communication Channels: Upward, Downward, Horizontal, and External. Focus on colleges, universities, and schools Volume 4, Number1, 2010. https://pdfs.semanticscholar.org/

[14] Marzano, R. \& Waters, T. (2010). District Leadership the Works: Striking the Right Balance, Bloomington, IN Solution TreeMOE (2008). Review of Ethiopian Education and Training Policy and Its Implementation. Executive Summary. Addis Ababa

[15] MOE (2010). Education Sector Development Program IV (ESDP): Program Action Plan, Federal Ministry of Education. Addis Ababa

[16] Musaazi, J. (2002). The Theory and Practice of Educational Administration. London and Basingstoke. Macmillan Publishers

[17] Oghuvbu, E. (2001). Determinants of Effective and Ineffective Supervision in Schools: Teachers Perspectives. Abraka, Nigeria: Delta State University

[18] Ojogwu, C. (2001). Supervision as an Instrument for Maintaining standard and Quality Control in Schools. A Lead Paper Presented at the First Annual National Conference

[19] Okendu, J.N.(2012a).The impact of school administrative structure and adequate supervision on the improvement of the Instructional Process. Academic Research Journal.Vol. 2(3)

[20] Olaleye, F.O (2013) Principals Organizational Management and Students Academic Achievement in Secondary Schools in Ekiti State Nigeria: Singaporean Journal Of Business Economics, And Management Studies Vol.2, No.2.

[21] Paqueo, V. B., J. R. G. Albert, and A. C. Orbeta. 2012. "A Critical Look at the Education Sector: Achievements, Challenges, and Reform Ideas. Chapter 3 of PIDS 2011 Economic Policy Monitor: Education for Development. Makati City.
[22] Peretomode, V. (1995). Introduction to Educational Administration, Planning and Supervision. Ikega: Joja Earch and Publishers Ltd.

[23] Rettig, P. (2007). Leslies Lament: How can I Make Teacher Supervision Meaningful? Education Horizons

[24] Roe, W. (1961). School Business Management. McGrow Hill Book Co. New York

[25] Schmoker, M. (2006). At Odds: Strategic Planning Learning Communities at the Crossroads, Towards the Best Schools We've Ever Had. Phi Delta Kappan

[26] Sergiovanni, T. (2009). The Principalship. A Reflective Practice Perspective, Boston: Pearson Educational Inc.

[27] Sergiovanni, T. \& Starratt, R. (2007) Supervision: A Redefinition (8th Ed.). New York: McGraw-Hill Companies, Inc.

[28] Starratt, R. (1997). Educational Supervision: Perspectives, Issues, and Controversies. Norwood, MA: Christopher Gordon Publisher

[29] Sule, M. (2013). The Effect pf Principal's Supervisory Demonstration Strategy on Teacher Job Efficiency in Nigerian Secondary School. IQSR Journal of Humanities and Social science.Vol. 2(1):pp.39 - 44.

[30] Tareilo, J. (2010). Other Side of the Desk: A 20/20 Look at the Principal ship. Lanham, MD: Rowman and Littlefield

[31] Visco, Dionisio A. (2015). Determinants of Performance in The Licensure Examination for Teachers (LET) of Abra State Institute of Sciences And Technology. International Journal of Research in Management \& Business Studies (IJRMBS 2015). Vol. 2 Issue 1 Jan. - Mar.2015. http://ijrmbs.com/vol2issue1/dionisio.pdf 